\title{
Minocycline but not valproic acid influence the density of NogoA-immunoreactive neurons in the hilus of the dentate gyrus of the rats subjected to intracerebral haematoma
}

\author{
K. Majak, B. Domaradzka-Pytel, P. Kowiański, J. Moryś \\ Department of Anatomy and Neurobiology, Medial University of Gdansk, Poland
}

[Received 31 March 2014; Accepted 16 April 2014]

\begin{abstract}
Intracerebral haemorrhage is a devastating neurological disease with high mortality rate and poor prognosis. The most prominent manifestation of the disease are the movement disorders, but many patients also suffer from cognitive impairment. Taking into account vulnerability of the neurons located within the hilus of the dentate gyrus (HDG) to many brain insults we decided to study the effect of experimentally induced intracerebral haematoma on density of neurons expressing NogoA protein in HDG. In addition, we studied how administration of valproic acid and minocycline, the two drugs generally believed to be neuroprotective agents, influences the density of these neurons. Our study revealed that 4 weeks after intracerebral haematoma induction, minocycline and valproic acid treatment increased the densities of NogoA-ir neurons in the hilus of contralateral dentate gyrus once the data were compared to ipsilateral hemispheres within the same group. The analysis of contralateral hemisphere data, however, revealed increased densities of NogoA-positive neurons in haematoma and valproic acid treated animals when compared to contralateral hemispheres of control animals. The administration of minocycline was, however, able to alleviate this increase. These changes may influence the haematoma-induced reorganisation of neuronal circuitries in the dentate gyrus. (Folia Morphol 2014; 73, 3: 279-285)
\end{abstract}

Key words: haemorrhage, hippocampal formation, stereology

\section{INTRODUCTION}

Intracerebral haemorrhage, a type of acute stroke, is a devastating neurological disease characterised with high mortality rate and poor prognosis. At present there are no effective drug therapies available. Therefore many human and experimental model studies focus on developing the treatment that would at least alleviate the brain damage or its consequences. Although the most prominent manifestation of the disease are the movement disorders, many patients also suffer from cognitive impairment. Deficits in hippocampus-dependent learning and memory processes have also been described both, in human and experimental models of the disease $[4,11,13,24]$.

In our study we focused on dentate gyrus. The major input to the dentate gyrus is provided by the entorhinal cortex via perforant pathway $[1,37]$, while dentate gyrus predominantly targets its projections to the CA3 field of hippocampus proper. Taking into account that the entorhinal cortex is the main source of sensory informa-

Address for correspondence: Dr K. Majak, Department of Anatomy and Neurobiology, Medial University of Gdansk, ul. Dębinki 1, 80-211 Gdańsk, Poland, tel:+48 58 3491401, fax:+48 58 3491421, e-mail: kmmajak@gumed.edu.pl 
tion that hippocampal formation utilizes to carry out its function, the dentate gyrus is considered to be the first step in processing of information leading to memory formation. The dentate gyrus is made of 3 cellular layers: relatively cell-free molecular layer, principal cell layer called granule cell layer and innermost polymorphic cell layer in which mossy cells are the most prominent $[2,14]$. The polymorphic cell layer is often referred as hilus of the dentate gyrus (HDG) $[1,37]$.

NogoA is a transmembrane protein of about 1200 amino acids $[5,10]$ and is one of the most potent neurite growth inhibitors in central nervous system (CNS) myelin and tissue [39]. NogoA is mainly expressed by oligodendrocytes in the adult CNS, but several brain regions containing NogoA-expressing neurons were also identified [12]. It is generally believed that NogoA expression in adult brain is characteristic for plastic CNS regions like cortex, dorsal root ganglia and of course hippocampus $[28,30,34]$. In human, increased immunoreactivity of NogoA-positive hippocampal neurons was observed in Alzheimer disease [9] and temporal lobe epilepsy [3]. The increase was also present in the experimental models of brain diseases including epilepsy $[28,41]$ or brain injury $[26,28,30]$.

Taking into account the presence of NogoA expressing neurons in HDG as well as vulnerability of the hilar region neurons, as demonstrated by studies on temporal lobe epilepsy or traumatic brain injury [19, 37], we decided to study the effect of experimentally induced intracerebral haematoma on density of NogoA-expressing neurons in HDG. In addition, we checked how valproic acid and minocycline, the two drugs widely reported to reduce the damage in several models of brain injury, influence the density of these neurons.

\section{MATERIALS AND METHODS}

\section{Animal procedures}

Twenty adult male Wistar rats (weighting 262-287 g) were housed individually in polycarbonate cages and had free access to water and food pellets. Temperature $\left(21.1^{\circ} \mathrm{C}\right.$ ) and lighting (light on from 7:00 am-7:00 pm) regimens were maintained at constant level.

The care and treatment of the rats conformed to the guidelines for laboratory animals established by the European Community Council Directive of 24 November 1986 (86/609/EEC), and the Local Ethical Committee of the Medical University of Gdansk. All the rats were divided into 4 experimental groups: control $(\mathrm{CON}, n=5)$, haematoma (HAEM, $n=5$ ), haematoma and minocyc- line (MINO, $n=5)$ and haematoma and valproic acid (VAL, $n=5$ ) groups. The control group comprised of animals that underwent the same surgical procedure as rats that were subjected to intracerebral haematoma (described below) with the exception of blood injection. In the study we used the experimental model of intracerebral haemorrhage described previously by Karwacki et al. [15-17] where detailed description of anaesthetic and surgical procedures were presented. Here we provide brief description of the experimental procedures used. In all the groups, the animals were generally anaesthetised with intraperitoneal injections of a mixture of fentanyl (Fentanyl, Polfa-Warszawa, Poland) with a dose of $0.02 \mu \mathrm{g} / \mathrm{kg}$ and dehydrobenzperidol (Droperidol, G. Richter; Hungary) with a dose of $0.75 \mu \mathrm{g} / \mathrm{kg}$. Then intubation tube was inserted to the trachea and the animals were mechanically ventilated with the Small Animal Ventilator SAR 830/p (CWE, Inc. USA), using a mixture of air and Sevoflurane (Baxter, Deerfield, IL, USA). Than the femoral artery was exposed and cannulated for blood sampling. Next, the animal was fixed in a stereotaxic frame and the skull was exposed. Then the whole was drilled in the skull in order to introduce the capillary into the left striatum. The stereotaxic coordinates for capillary placement (3.3 $\mathrm{mm}$ posteriorly, $6.0 \mathrm{~mm}$ left and $9.0 \mathrm{~mm}$ ventrally to the bregma) were based on rat brain atlas of Paxinos and Watson [32]. After introducing the capillary into the brain the $150 \mu \mathrm{L}$ of autologous arterial blood was injected for $10 \mathrm{~min}$. The capillary was left in place for another $5 \mathrm{~min}$, than it was slowly withdrawn. Two rats ( 1 in HAEM and 1 in VAL groups) died within the first 24-h after haematoma induction; therefore the final analysis in these two experimental groups was performed on 4 animals.

\section{Medication}

Two hours after completing the surgery procedures rats assign to MINO and VAL groups received twice per day (for 7 consecutive days) intraperitoneal injections of minocycline (M9511, Sigma-Aldrich GmbH, Germany; $45 \mathrm{mg} / \mathrm{kg}$ ) or valproic acid (P4543, Sigma-Aldrich $\mathrm{GmbH}$, Germany; $200 \mathrm{mg} / \mathrm{kg}$ following loading dose of $400 \mathrm{mg} / \mathrm{kg}$ ) dissolved in $2 \mathrm{~mL}$ of $0.09 \%$ saline (Polpharma, Poland). The CON and HAEM animals received $2 \mathrm{~mL}$ of saline injections only.

\section{Tissue collection and preparation}

Four weeks after haematoma induction rats were deeply anaesthetised (Thiopental, $100 \mathrm{mg} / \mathrm{kg}$, i.p.) and 

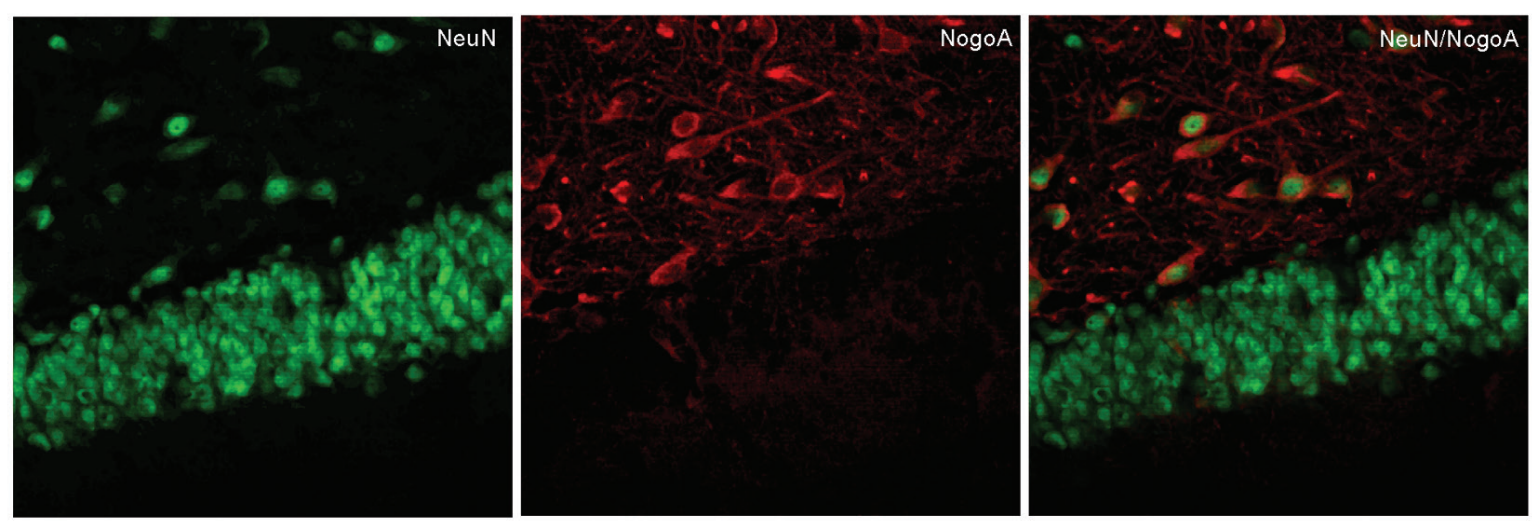

Figure 1. Confocal microphotograph presenting NeuN-ir nuclei, NogoA-positive cytoplasm and merged picture of neurons located in the hilus of dentate gyrus contralateral to intracerebral haematoma in valproic acid-treated rat. The pictures were taken under magnification $\times 40$.

initially flushed transcardially with the $0.9 \%$ sodium chloride and then perfused with $4 \%$ paraformaldehyde in the $0.1 \mathrm{M}$ phosphate buffer at $4^{\circ} \mathrm{C}$. Subsequently, the brains were removed, post-fixed for $2 \mathrm{~h}$ in the perfusing solution and then cryoprotected by immersion in $30 \%$ sucrose at $4^{\circ} \mathrm{C}$ until they sunk. Next, the brains were cut into $40 \mu \mathrm{m}$ coronal sections cryostat (Jung CM1800, Leica, Germany) and stored in tissue collecting solution (30\% ethylene glycol, $25 \%$ glycerol in $0.05 \mathrm{M}$ sodium phosphate buffer) at $-20^{\circ} \mathrm{C}$ until further processing.

\section{Nissl staining and immunohistochemistry}

To assess the cytoarchitectonic boundaries of the dentate gyrus one series of sections was stained with $10 \%$ cresyl violet. The remaining series of sections were double-labelled with standard immunohistochemical protocols using antibodies against the NogoA and neuronal marker NeuN. Briefly, after 3 washings (15 min each) in phosphate buffered saline, sections were blocked in 5\% normal goat serum and $0.3 \%$ Triton X-100 for $2.5 \mathrm{~h}$ at room temperature. For double staining, sections were first incubated with a cocktail of primary containing 1:200 solution of a rabbit polyclonal NogoA antibody (sc-25660, Santa Cruz Biotechnology, Inc., Dallas, TX, USA) and 1:300 solution mouse monoclonal NeuN antibody (MAB377, Millipore Corporation, Billerica, MA, USA) for 3 days at room temperature. Then the sections were washed 3 times for $15 \mathrm{~min}$ in $0.01 \mathrm{M}$ PBS and incubated for $2.5 \mathrm{~h}$ at room temperature with the secondary antibodies cocktail containing 1:600 goat anti-rabbit conjugated with Сy3 (\#111-165-144, Jacksom ImmunoResearch Laboratories, West Grove, PA, USA) and 1:150 goat anti-mouse conjugated with Alexa Fluor 488 (A-11001, Molecular Probes, Eugene, OR, USA). Finally, the sections were washed, mounted on slides and coverslipped with Kaiser's Glyceringelatine (\#A12083, Merck, Germany). Specificity of the immunostaining was checked by omitting either the primary or secondary antibodies which resulted in total disappearance of the staining.

\section{Quantitative and statistical analysis}

The CAST-Grid (Olympus, Denmark) image analysis system (LaserPix v. 4.0, BioRad, UK) and a 40 objective lens were employed to assess the number of NogoA-positive cells in the hilus of dentate gyrus in both hemispheres. The HDG was outlined and computer-aided estimation was used to estimate the number of NogoA-ir cell profiles per unit area for each investigated hippocampal structure. The grid size was either $4067 \mu \mathrm{m}^{2}$. At least one-half of the area of a given section was analysed; the first test area was chosen randomly and the remaining ones were selected by systematic random sampling. Statistical analysis was performed using KyPlot (v. 2.0) software. To compare the densities of NogoA-ir neurons between ipsiand contralateral hemispheres in each experimental group, Mann-Whitney U Test was applied. To compare the data from ipsi- or contralateral hemispheres to controls and between groups Steel and Steel-Dwass Tests were used, respectively. Significant values were set at $p<0.05$.

\section{RESULTS}

Double labelled immunostaining revealed that within the HDG nearly all NogoA-ir cells were also NeuN-positive, therefore we considered them neurons (Fig. 1). The remaining NogoA-positive cells were presumably oligdendrocytes because they did not express typical neuronal morphology as well as 


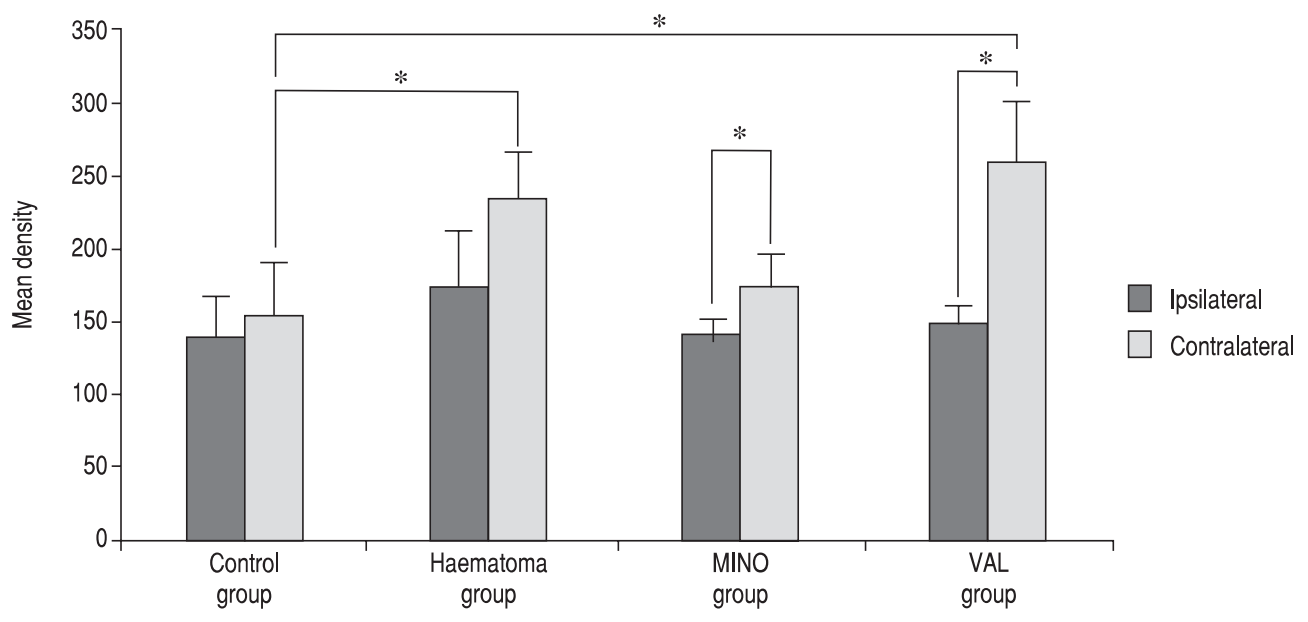

Figure 2. The densities of NogoA-ir neurons ( \pm standard deviation) in the hilus of dentate gyrus of ipsi- and contralateral hemispheres 4 weeks after induction of intracerebral haematoma in all experimental groups. Statistical significances marked with * $p<0.05$ (Mann-Whitney U test, Steel test); MINO — haematoma and minocycline group; VAL — haematoma and valproic acid group.

microglial (Ox6, OX42) or astroglial markers (GFAP) (unpublished data).

Comparisons of the densities of NogoA-ir neurons in HDG between hemispheres ipsi- and contralateral to the haematoma revealed no difference in control and haematoma groups. On the other hand the densities were significantly increased in contralateral hemispheres, when compared to ipsilateral ones, in minocycline and valproic acid treated animals ( $p<0.05$, Mann-Whitney $U$ test) (Fig. 2).

Next we compared the densities of NogoA-ir neurons in ipsilateral hemispheres to control groups and among all experimental groups. The analysis revealed no differences between them (Fig. 2). Similar analysis performed for contralateral hemispheres, however, disclosed the higher densities of NogoA cells in haematoma and valproic acid-treated animals when compared to controls $(p<0.05$, Steel test) (Fig. 2).

\section{DISCUSSION}

Our study revealed that 4 weeks after intracerebral haematoma induction, minocycline and valproic acid treatment increased the densities of NogoA-ir neurons in the hilus of contralateral dentate gyrus once the data were compared to ipsilateral hemispheres within the same group. Interestingly, the analysis of contralateral hemisphere data from different experimental groups disclosed increase in densities of NogoA-positive neurons in haematoma and valproic acid treated animals when compared to contralateral hemispheres of control animals. No such effect was observed in minocycline-treated rats.

NogoA was first identified as a myelin-associated protein expressed in mature oligodendrocytes, but recently its presence has been demonstrated in several CNS regions, both in developing and mature neurons. During development, Nogo-A influences migration and neurite outgrowth of cortical neurons [31], conducts corticospinal axons growing along the spinal cord, and regulates the progressive restriction of plasticity $[8,27]$. Few data from studies on adult brains have been published suggesting that NogoA constitutively controls the architecture of neurons in the intact hippocampus (mainly via a receptor mediated mechanisms) $[33,44]$. Moreover, electrophysiological studies revealed that NogoA or NogoA receptor neutralisation significantly increased the long term potentiation in hippocampal neurons [7]. It may indicate unique role of NogoA signalling in restricting physiological synaptic plasticity. Therefore NogoA may serve as important negative regulator of functional and structural plasticity in mature neuronal networks in the adult hippocampus. Majority of the NogoA studies, however, focused on its crucial role in preventing repair processes in different CNS injuries and diseases (for review see [12, 34]). For example, in spinal cord lesion and ischaemic stroke models application of various NogoA antibodies or reagents blocking Nogo receptor NgR1 resulted in long-range axons regeneration and increased compensatory growth of intact fibres or at least significantly improved 
functional recovery [34]. The concept of therapeutic antibody administration has been tested in clinical trials in para- and tetraplegic patients as well as in amyotrophic lateral sclerosis (due to the fact that NogoA is ectopically expressed in neuromuscular junction as an early sign of the disease) [34]. On the other hand, in the wild type mice with NogoA blockage (by antibodies) or in NogoA knock-out mice subjected to middle cerebral artery occlusion [20], observed decreased neuronal survival when compared to control groups. In addition, NogoA delta 20 transfection in cortical neurons protected the cells from oxidative stress in vitro [29]. Based on that one can believe that at NogoA expressed in neurons might also act as a neuroprotective agent. In our study however, we observed increase in density of NogoA neurons in contralateral HDG of rats subjected to intracerebral haematoma. Therefore we rather believe that this increase is related to negative consequences of brain insult.

Valproic acid and minocycline has been considered a neuroprotective agents in several models of brain injuries and diseases [18, 23, 35, 43]. Neuroprotective effect of minocycline may be attributable to its antiapoptotic, antioxidative and anti-inflammatory actions $[18,22]$. In the experimental models of intracerebral haemorrhage models minocycline was shown to inhibit some inflammatory-related genes [42] as well as microglial/macrophage activation in peri-infarct region [43]. Study of Xue et al. [43] demonstrated that minocycline also alleviated neuronal cell death and improve behavioural recovery. On the other hand, no reduction of infarct volume or functional benefit was observed by Szymanska et al. [40]. Our analysis revealed that administration of minocycline, started $2 \mathrm{~h}$ after induction of intracerebral haematoma, is able to prevent the increase of NogoA-ir in HDG neurons in contralateral hemisphere.

Existing data on mouse model of intracerebral haemorrhage (induced by collagenase injections) suggests that the administration of valproic acid inhibits haematoma expansion, perihaematomal cell death, caspase activation and inflammatory cell infiltration which results in behavioural improvement tested 4 weeks later [38]. Similar effects (on infarct volume, inflammation or behavioural outcome) were observed in murine models of ischaemic stroke $[21,36]$ or traumatic brain injury [6]. It, however, looks like that beneficial effects observed the haematoma lodge cannot be observed in the HDG because in the contralateral hemisphere the density of NogoA-positive neurons was higher than in sham-operated controls and similar increase was observed in rats with induced haematoma that did not received any drug treatment. Therefore positive effects of valproate acid treatment may be observed in brain region affected directly by the insult but not necessarily in the structures in which neurodegeneration develops as a consequence of primary insult. In addition, we always have to take into consideration that different experimental models used, time window between the insult and beginning of drug treatment as well as drug administration schemes may significantly influence obtained results.

The other thing, that has to be discussed is the presence of the changes in the dentate gyrus contralateral to the haematoma. The presence of strong commissural/association projection to corresponding contralateral dentate gyrus (including hilus) has been well characterised feature of HDG neurons [2, 37]. Via this projection pathological processes in the ipsilateral hemisphere may affect the contralateral side later on. For example, following kainate injection into CA3 sector of hippocampus different subpopulations of cells degenerated at different times in contralateral hilum or CA1 and CA3 sectors of hippocampus [25]. But in this study the "primary" injury was applied directly to hippocampus. Once the injury site was located outside the hippocampus more time was needed to observe changes in hippocampus ipsilateral to injury site. For example, Takeda et al. [41] used amygdala kindling model of temporal lobe epilepsy. They observed that Nogo-A expression in the ipsilateral CA2 and CA3 sectors of hippocampus gradually increased with the development of kindling, but no increase was observed in the contralateral hippocampus as the rats advanced to stage 5 of amygdala kindled seizures. The time the animals reached stage 5 seizures differed between animals, but it did not exceed 10 days which may explain no changes observed in contralateral side. In the fluid percussion model of traumatic brain injury applied to frontoparietal cortex, numerous NogoA-ir neurons were observed in the hilus of the dentate gyrus of sham-injured rats. These neurons in the ipsilateral HDG were found to be selectively vulnerable to injury and their number was decreased 7 days after injury [26]. Unfortunately, analysis of contralateral hippocampus was performed in this study. The analysis of both, ipsi- and contralateral sides, were made by Meier et al. [28]. In their study they evaluated the level of NogoA mRNA after deafferentation of hippocampus by electrocoaglu- 
lation of entorhinal cortex. In the HDG of ipsi- and contralateral hippocampi they observe more than 30-fold increase during early phase of lesioning, but the level was decreased below control level at 15-21 days post injury. In their study NogoA mRNA was also upregulated 5 days after intraperitoneal injections of kainic acid. On the other hand, Mignorance et al. [30] observed opposite effects using similar lesions. Twenty four hours after kainite injections Nogo mRNA was strongly downregulated and only slight transient upregulation of Nogo mRNA was noticed in the ipsilateral hippocampus (including dentate gyrus) 3 days after entorhinal cortex lesions. No changes were observed contralaterally. Differences in the in situ hybridisation probes as well as NogoA protein domain recognised by the antibodies employed in these studies are likely to be responsible for such discrepancies. In our study, we found significant increase in densities of neurons expressing NogoA protein in the contralateral HDG, but no changes were observed in ipsilateral hemispheres. It is, however, important to remember that our analysis was performed 4 weeks following intracerebral haematoma induced in striatum, so there is a strong possibility that at this time point changes could be limited to contralateral hemisphere only. In addition, different type of primary brain injury, antibodies used and quantification methods might have influenced the results.

\section{CONCLUSIONS}

The role of neuronal NogoA expression remains unclear. It was, however, implicated that this protein is highly expressed in brain regions strongly involved in neuronal plasticity and its level of expression is also influenced by pathological processes changing the reorganisation of neuronal circuitries. Taking into account that HDG neurons control the excitability of dentate gyrus granule cells, increased expression of NogoA in these neurons may suggest that intracerebral haematoma induces formation of new synaptic contacts or at least reorganisation of existing circuitries. The administration of minocycline that alleviates the increase may influence these processes. Whether these changes affect hippocampal-dependent cognitive outcome requires further studies.

\section{ACKNOWLEDGEMENTS}

The study was financially supported by Polish Ministry of Science and Higher Education grant N N303 341935.
The Authors would like to express their gratitude to dr Jan H. Spodnik and dr Jerzy Dziewiątkowski for providing the expert feedback in confocal microscopy and statistics.

\section{REFERENCES}

1. Amaral DG (1978) A Golgi study of cell types in the hilar region of the hippocampus in the rat. J Comp Neurol, 182: 851-914.

2. Amaral DG, Scharfman HE, Lavenex $P$ (2007) The dentate gyrus: fundamental neuroanatomical organization (dentate gyrus for dummies). Prog Brain Res, 163: 3-22.

3. Bandtlow CE, Dlaska M, Pirker S, Czech T, Baumgartner C, Sperk G (2004) Increased expression of Nogo-A in hippocampal neurons of patients with temporal lobe epilepsy. Eur J Neurosci, 20: 195-206.

4. Brand C, Alber B, Fladung AK, Knauer K, König R, Oechsner A, Schneider IL, Tumani H, Widder B, Wirtz CR, Woischneck D, Kapapa T (2014) Cognitive performance following spontaneous subarachnoid haemorrhage versus other forms of intracranial haemorrhage. Br J Neurosurg, 28: 68-80.

5. Chen MS, Huber $A B$, van der Haar ME, Frank $M$, Schnell $L$, Spillmann AA, Christ F, Schwab ME (2000) Nogo-A is a myelin-associated neurite outgrowth inhibitor and an antigen for monoclonal antibody IN-1. Nature, 403: 434-439.

6. Dash PK, Orsi SA, Zhang M, Grill RJ, Pati S, Zhao J, Moore AN (2010) Valproate administered after traumatic brain injury provides neuroprotection and improves cognitive function in rats. PLoS One, 5: e11383.

7. Delekate A, Zagrebelsky M, Kramer S, Schwab ME, Korte M (2011) NogoA restricts synaptic plasticity in the adult hippocampus on a fast time scale. Proc Natl Acad Sci USA, 108: 2569-2574.

8. Gianola S, Savio T, Schwab ME, Rossi F (2003) Cell-autonomous mechanisms and myelin-associated factors contribute to the development of Purkinje axon intracortical plexus in the rat cerebellum. J Neurosci, 23: 4613-4624.

9. Gil V, Nicolas O, Mingorance A., Ureña JM, Tang BL, Hirata T, Sáez-Valero J, Ferrer I, Soriano E, del Río JA (2006) Nogo-A expression in the human hippocampus in normal aging and in Alzheimer disease. J Neuropathol Exp Neurol, 65: 433-444.

10. GrandPre T, Nakamura F, Vartanian T, Strittmatter SM (2000) Identification of the Nogo inhibitor of axon regeneration as a Reticulon protein. Nature, 403: 439-444.

11. Hartman R, Lekic T, Rojas H, Tang J, Zhang J H (2009) Assessing functional outcomes following intracerebral hemorrhage in rats. Brain Res, 1280: 148-157.

12. Hunt D, Coffin RS, Prinjha RK, Campbell G, Anderson PN (2003) Nogo-A expression in the intact and injured nervous system. Mol Cell Neurosci, 24: 1083-1102.

13. Hwang L, Choi IY, Kim SE, Ko IG, Shin MS, Kim CJ, Kim SH, Jin JJ, Chung JY, Yi JW (2013) Dexmedetomidine ameliorates intracerebral hemorrhage-induced memory impairment by inhibiting apoptosis and enhancing brain-derived neurotrophic factor expression in the rat hippocampus. Int J Mol Med, 31: 1047-1056.

14. Jinde S, Zsiros V, Nakazawa K (2013) Hilar mossy cell circuitry controlling dentate granule cell excitability. Front Neural Circuits, 7: 14 
15. Karwacki Z, Kowiański P, Dziewiątkowski J, Domaradzka-Pytel B, Ludkiewcz B, Wójcik S, Narkiewicz O, Moryś J (2005a) The influence of sevoflurane on the reactivity of astrocytes in the course of the experimental intracerebral haemorrhage in rat. J Physiol Pharmacol, 56: 455-469.

16. Karwacki Z, Kowiański P, Dziewiątkowski J, Domaradzka-Pytel B, Ludkiewcz B, Wójcik S, Narkiewicz O, Moryś J (2005b) Apoptosis in the course of experimetal intracerebral haemorrhage in the rat. Folia Morphol, 64: 248-252.

17. Karwacki Z, Kowiański P, Dziewiątkowski J, Domaradzka-Pytel B, Ludkiewicz B, Wójcik S, Narkiewicz O, Moryś J (2006) Quantitative analysis of influence of sevoflurane on the reactivity of microglial cells in the course of the experimental model of intracerebral haemorrhage. Eur J Anaesthesiol, 23: 874-881.

18. Katsuki H (2010) Exploring neuroprotective drug therapies for intracerebral hemorrhage. J Pharmacol Sci, 114: 366-378.

19. Kharatishvili I, Nissinen JP, McIntosh TK, Pitkänen A (2006) A model of posttraumatic epilepsy induced by lateral fluid-percussion brain injury in rats. Neuroscience, 140: 685-697.

20. Kilic E, ElAli A, Kilic U, Guo Z, Ugur M, Uslu U, Bassetti CL, Schwab ME, Hermann DM (2010) Role of Nogo-A in neuronal survival in the reperfused ischemic brain. J Cereb Blood Flow Metab, 30: 969-984.

21. Kim HJ, Rowe M, Ren M, Hong JS, Chen PS, Chuang DM (2007a) Histone deacetylase inhibitors exhibit anti-inflammatory and neuroprotective effects in a rat permanent ischemic model of stroke: multiple mechanisms of actionn. J Pharmacol Exp Ther, 321: 892-901.

22. Kim HS, Suh YH (2009) Minocycline and neurodegenerative diseases. Behav Brain Res, 196: 168-179.

23. LauterbachEC, VictoroffJ, Coburn KL, ShillcuttSD, Doonan SM, Mendez MF (2010) Psychopharmacological neuroprotection in neurodegenerative disease: assessing the preclinical data. J Neuropsychiatry Clin Neurosci, 22: 8-18.

24. MacLellan CL, Langdon KD, Churchill KP, Granter-Button S, Corbett D (2009) Assessing cognitive function after intracerebral hemorrhage in rats. Behav Brain Res, 198: 321-328.

25. Magloczky Z, Freund TF (1995) Delayed cell death in the contralateral hippocampus following kainate injection into the CA3 subfield. Neuroscience, 66: 847-860.

26. Marklund N, Fulp CT, Shimizu S, Puri R, McMillan A, Strittmatter SM, McIntosh TK (2006) Selective temporal and regional alterations of Nogo-A and small proline-rich repeat protein 1A (SPRR1A) but not Nogo-66 receptor $(\mathrm{NgR})$ occur following traumatic brain injury in the rat. Exp Neurol, 197: 70-83.

27. McGee AW, Yang Y, Fischer QS, Daw NW, Strittmatter SM (2005) Experience-driven plasticity of visual cortex limited by myelin and Nogo receptor. Science, 309: 2222-2226.

28. Meier S, Bräuer AU, Heimrich B, Schwab ME, Nitsch R, Savaskan NE (2003a) Molecular analysis of Nogo expression in the hippocampus during development and following lesion and seizure. FASEB J, 17: 1153-1155.

29. Mi YJ, Hou B, Liao QM, Ma Y, Luo Q, Dai YK, Ju G, Jin WL (2012) Amino-Nogo-A antagonizes reactive oxygen spe- cies generation and protects immature primary cortical neurons from oxidative toxicity. Cell Death Differ, 19: 1175-1186.

30. Mingorance $A$, Fontana $X$, Solé $M$, Burgaya $F$, Ureña JM, Teng FY, Tang BL, Hunt D, Anderson PN, Bethea JR, Schwab ME, Soriano E, del Río JA (2004) Regulation of Nogo and Nogo receptor during the development of the entorhino-hippocampal pathway and after adult hippocampal lesions. Mol Cell Neurosci, 26: 34-49.

31. Mingorance-Le Meur A, Zheng B, Soriano E, del Río JA (2007) Involvement of the myelin-associated inhibitor Nogo-A in early cortical development and neuronal maturation. Cereb Cortex, 17: 2375-2386.

32. Paxinos G, Watson C (1986a) The rat brain in stereotaxic coordinates. 2nd Ed. Academic Press, New York.

33. Peng X, Kim J, Zhou Z, Fink DJ, Mata M (2011) Neuronal Nogo-A regulates glutamate receptor subunit expression in hippocampal neurons. J Neurochem, 119: 1183-1193.

34. Pernet V, Schwab ME (2012) The role of Nogo-A in axonal plasticity, regrowth and repair. Cell Tissue Res, 349: 97-104.

35. Plane JM, Shen Y, Pleasure DE, Deng W (2010) Prospects for minocycline neuroprotection. Arch Neurol, 67: 1442-1448.

36. Qian YR, Lee MJ, Hwang S, Kook JH, Kim JK, Bae CS (2010) Neuroprotection by valproic Acid in mouse models of permanent and transient focal cerebral ischemia. Korean J Physiol Pharmacol, 14: 435-440.

37. Scharfman HE, Myers CE (2012) Hilar mossy cells of the dentate gyrus: a historical perspective. Front Neural Circuits, 6: 106.

38. Sinn DI, Kim SJ, Chu K, Jung KH, Lee ST, Song EC, Kim JM, Park DK, Kun Lee S, Kim M, Roh JK (2007) Valproic acid-mediated neuroprotection in intracerebral hemorrhage via histone deacetylase inhibition and transcriptional activation. Neurobiol Dis, 26: 464-472.

39. Spillmann AA, Bandtlow CE, Lottspeich F, Keller F, Schwab ME (1998) Identification and characterization of a bovine neurite growth inhibitor (bNl-220). J Biol Chem, 273: 19283-19293.

40. Szymanska A, Biernaskie J, Laidley D, Granter-Button S, Corbett D (2006) Minocycline and intracerebral hemorrhage: influence of injury severity and delay to treatment. Exp Neurol, 197: 189-196.

41. Takeda Y, Kamida T, Fujiki M, Kobayashi H (2007a) Hippocampal Nogo-A and neo-Timm's staining in amygdala kindling rats. Neurol Res, 29: 199-203.

42. Wasserman JK, Zhu X, Schlichter LC (2007) Evolution of the inflammatory response in the brain following intracerebral hemorrhage and effects of delayed minocycline treatment. Brain Res, 1180: 140-154.

43. Xue M, Mikliaeva El, Casha S, Zygun D, DemchukA, Yong VW (2010a) Improving outcomes of neuroprotection by minocycline: guides from cell culture and intracerebral hemorrhage in mice. Am J Pathol, 176: 1193-1202.

44. Zagrebelsky M, Schweigreiter R, Bandtlow CE, Schwab ME, Korte M (2010) Nogo-A stabilizes the architecture of hippocampal neurons. J Neurosci, 30: 13220-13234. 